\title{
O "NOVO" ESTATUTO JURÍDICO DOS ANIMAIS NÃO-HUMANOS EM PORTUGAL
}

\author{
Ana Elisabete FERREIRA ${ }^{1}$ \\ Eduardo António da Silva FIGUEIREDO²
}

ISSUE DOI: $10.21207 / 1983.4225 .1013$

\section{RESUMO}

No presente artigo, os autores propõem-se a aflorar as principais teses em matéria de estatuto (jurídico) dos animais não-humanos, concluindo pela adequação dogmática e prática daquela que advoga o reconhecimento de deveres dos seres humanos que têm por objeto os animais. Em seguida, questionam a existência de um estatuto jurídico-constitucional do animal na ordem jurídica lusa e analisam as repercussões das recentes inovações legislativas nesta matéria, quer no âmbito civil, quer penal. Apesar do caminho trilhado ser favorável à tutela e efetivação do bem-estar animal, a querela afigura-se complexa e polémica, alertando para a necessidade de se repensar a arquitetura dos sistemas jurídicos, bem como as premissas axiológico-valorativas que os fundam.

Palavras-chave: Estatuto jurídico dos animais; Bem-estar animal; Direito Civil; Direito Constitucional; Direito Penal.

\section{ABSTRACT}

In this paper, the authors propose to bring out the main theses regarding the (legal) status of nonhuman animals, concluding by the dogmatic and practical adequacy of that which advocates the

\footnotetext{
${ }^{1}$ Doutoranda em Bioética pela Universidade Católica Portuguesa (UCP), Lisba, Portugal. Investigadora do Centro de Direito Biomédico da FDUC. Docente convidada da Escola Superior de Saúde de Viseu. Membro do Órgão de Bem-Estar Animal da Faculdade de Medicina da Universidade do Porto. Advogada.

2 Assistente Convidado da Secção da Ciências Jurídico-Políticas da Faculdade de Direito da Universidade de Coimbra (UC), coimbra, Portugal. Investigador do Centro de Direito Biomédico da FDUC.
} 
recognition of the duties of human beings whose object is animals. Then, they question the existence of a legal-constitutional status of the animal in the Portuguese legal order and analyze the repercussions of recent legislative innovations in this matter, both in the civil and criminal spheres. Despite the fact that the path taken is favorable to the protection and effectiveness of animal welfare, the dispute seems complex and controversial, alerting to the need to rethink the architecture of the legal systems, as well as the axiological-evaluative premises that found them.

Keywords: Legal status of animals; Animal welfare; Civil right; Constitutional right; Criminal Law.

\section{INTRODUÇÃO}

Como é comummente sabido, seres humanos e animais nãohumanos "dividem a terra, habitat comum que partilham, mas vivem em mundos paralelos, separados pelo Direito", pela filosofia e até mesmo pela (bio)ética ${ }^{3}$. O estatuto (jurídico) do animal evoluiu ao longo do tempo, sendo identificáveis inúmeras diferenças no modo como o Homem tem encarado (e se tem relacionado com) os animais não-humanos. Durante vários séculos, e encontrando fundamento, inter alia, na clássica desconsideração aristotélica - a qual, baseada numa instrumentalizante "escala dos seres", propugna que "se a natureza nada faz de imperfeito ou em vão, então, necessariamente criou todos os seres em função do homem" ${ }^{4}$ - ou no polémico mecanicismo cartesiano - que vislumbra o animal não-humano como um mero autómato, desprovido de alma racional e, portanto, de qualquer dimensão espiritual ${ }^{5}-$, o ser humano vislumbrou o animal como um mero meio para se atingir um fim ${ }^{6}$, uma "coisa"

\footnotetext{
${ }^{3}$ Duarte, Maria Luísa, “Direito da união europeia e estatuto jurídico dos animais: uma grande ilusão?", in Direito (do) Animal (Coord. por Maria Luísa Duarte e Carla Amado Gomes), Coimbra: Almedina, 2016, p. 224.

${ }^{4}$ Aristóteles, Política, Lisboa: Vega, 1998, p. 75.

${ }^{5}$ Defendia R. Descartes que "os animais não passam, na verdade, de máquinas particularmente intrincadas... autómatos destituídos de pensamento ou de qualquer consciência". Uma tal visão contribuiu, como nos dá conta Ian Robertson, para que a estes fosse negada "até a mais ínfima consideração humana no âmbito da agricultura comercial ou da vivissecção". Cf. Cabral, Filipe, Fundamentação dos direitos dos animais: a existencialidade jurídica, Alcochete: Alfarroba, 2015, p. 50; e ainda, Robertson, Ian, Animals, welfare and the Law: fundamental principles for critical assessment, United Kingdom: Earthscan - Routledge, 2015, p. 55.

${ }^{6}$ Partindo do princípio de que a racionalidade se circunscreve apenas à esfera do ser humano, I. Kant chegou a afirmar que "os animais são meros meios para se atingir um fim. Esse fim é o Homem". Ainda assim, este tem o dever de não praticar atos de crueldade para com os animais não-humanos, não "por assim os [tratar] de forma errada, mas porque essa crueldade pode levar as pessoas a serem cruéis umas com as outras". As referências foram encontradas em Fernandes, Miguel Lemos, "Animais experimentais? Só o rato do computador!", in Direito (do) Animal (Coord. por Maria Luísa Duarte e Carla Amado Gomes), Coimbra: Almedina, 2016, p. 288.
} 
desprovida de sensações e emoções e, por isso, passível de ser colocada, de forma legítima e ilimitada, ao serviço do Homem e dos seus interesses.

A grande viragem no modo como a Humanidade encara o animal não-humano verificou-se, na opinião de grande parte da doutrina, com a publicação, já no séc. XVIII, da obra Introduction to the Principles of Morals and Legislation de JEREMY BENTHAM, na qual o mesmo afirmava que 'a questão não é 'podem eles raciocinar?' ou 'podem eles comunicar?', mas antes 'podem eles sofrer?'”. Desta forma, partindo de uma matriz utilitarista já antecipada por DAVID HUME, considera-se que seres humanos e animais não-humanos partilham entre si o desígnio de buscar o prazer e evitar a dor e o sofrimento. E note-se, na visão do autor, a capacidade de sofrer - a qual depende unicamente da dotação de consciência e não de uma certa dose de racionalidade inspirada num qualquer paradigma onto-antropológico7 - é "não apenas condição necessária, mas suficiente, para se ser sujeito de consideração éticojurídica"8.

É certo que os reflexos desta obra na transformação da relação entre os seres humanos e os animais só mais tarde se vieram a manifestar, mormente com o surgimento de inúmeras correntes defensoras do bemestar animal (as chamadas correntes bem-estaristas) ou inclusive da sua personificação e consequente reconhecimento enquanto "sujeitos de direito" (as correntes dos direitos) ${ }^{9} /{ }^{10}$. Em suma, no primeiro caso, colocase em destaque a proteção do seu bem-estar, considerando-se "secundária ou mesmo inconveniente a questão da natureza jurídica do animal e a sua autonomia ou idoneidade como centro de imputação de verdadeiros direitos" - destacando-se, nesta senda, a posição de PETER SINGER,

\footnotetext{
${ }^{7}$ Cabral, Filipe, Fundamentação dos direitos dos animais: a existencialidade jurídica, 71.

${ }^{8}$ Ibidem.

${ }^{9}$ Há quem vá ainda mais longe, seguindo os passos da Deep Ecology Doctrine, e reconheça à natureza (e, por essa via, também aos animais não-humanos) um valor superior ao do ser humano. Cf. Gassiot, Olivier, "L'animal, nouvel objet du droit constitutionnel”, in Revue Française de Droit Constitutionnel, n. ${ }^{\circ} 64,2005$, p. 704.

${ }^{10}$ Fernando Araújo propõe-nos uma outra síntese, baseada na distinção entre teses diretas e indiretas. No quadro das primeiras, encontramos as interpretações inigualitárias (que, não obstante aceitem a desigualdade dos animais face aos seres humanos, propõem a necessidade de consideração direta dos interesses daqueles) e as interpretações igualitárias (que "consideram que os animais são merecedores de uma consideração valorativa direta e do reconhecimento de um estatuto moral e jurídico em paridade com o dos humanos"). Por sua vez, as teses indiretas partem do pressuposto que os animais só nos são "indiretamente [relevantes] porque a lesão de um interesse de um animal há-de ser a lesão direta do património do seu proprietário ou daqueles cuja sensibilidade seja gravemente afetada pelo tratamento inconsiderado dos interesses de um não-humano". Cf. Araújo, Fernando, A hora dos direitos dos animais, Coimbra: Almedina, 2003, p. 334 e ss.
} 
baseada num princípio de igualdade na consideração dos interesses e focada no combate exemplar do especismo; no segundo caso, defende-se a imperatividade do reconhecimento do animal não-humano como autêntico titular de direitos que o "libertem e protejam de todas as formas de exploração e de inflição de sofrimento para benefício da espécie humana" - destacando-se, neste sentido, a obra de TOM REGAN ${ }^{11}{ }^{12}$.

A estas correntes "clássicas" acrescentaremos uma outra que tem ganho destaque por parte da doutrina. Segundo alguns autores, a proteção dos interesses dos animais, enquanto seres sensíveis, é mais efetiva se se apostar na defesa séria e compreensiva da existência de deveres (dos seres humanos) de promoção e efetivação do seu bem-estar ${ }^{13}$. Paradigmaticamente, ARTHUR KAUFMANN considera que o reconhecimento de direitos aos animais tanto não alteraria substancialmente o seu estatuto ou reforçaria a sua proteção - que é uma finalidade que, quer no plano teorético, quer prático, pode ser alcançada através do mero reconhecimento da existência de deveres do Homem que têm por objeto os animais, naturalmente acompanhado da previsão de consequências jurídicas relevantes em caso de incumprimento dos mesmos ${ }^{14}$-, como poderia implicar que se caísse em discursos extremados e demasiado focados numa "pessoalização do animal", quando se sabe que eles não reúnem as caraterísticas que (pelo menos, hodiernamente) são

\footnotetext{
${ }^{11}$ A defesa do reconhecimento de direitos dos animais foi levada a cabo por muitos outros autores: por exemplo, em 1802, John Lawrence defendeu os chamados "direitos das bestas", propondo a sua proteção pelo "mesmo manto que cobre a humanidade". Outros autores que, historicamente, se destacaram na defesa desta tese (é certo, com diferenças e particularidades consideráveis) foram Edward Nicholson e Henry Salt (aliás, é de notar que este último foi um dos grandes críticos da vivissecção, que qualificava como uma "violação deliberada e declarada dos direitos dos animais"). Cf. Cabral, Filipe, Fundamentação dos direitos dos animais: a existencialidade jurídica, 82 e ss.

${ }^{12}$ Por todos, Duarte, Maria Luísa, "Direito da união europeia e estatuto jurídico dos animais: uma grande ilusão?", 225.

${ }^{13}$ Entre nós, João Carlos Loureiro defende esta mesma tese, esclarecendo que tais deveres apenas podem ser entendidos como autênticos "deveres que têm como objeto os animais, mas [já] não de deveres para com os animais". Cf. Loureiro, João, Constituição e Biomedicina - Vol. II, Coimbra: Faculdade de Direito da Universidade de Coimbra, 2003, p. 903.

${ }^{14}$ KAUFMANN, Arthur, Filosofia do Direito, 2. ${ }^{a}$ Edição, Lisboa: Fundação Calouste Gulbenkian, 2007, p. 452.
} 
reconhecidas às pessoas e que, por enquanto, se encontram limitadas ao universo dos seres humanos ${ }^{15} / 16$.

Após esta breve incursão por alguns dos principais tópicos de discussão no âmbito da polémica questão do estatuto (jurídico) dos animais não-humanos, olhemos para o ordenamento jurídico português e tracemos, ainda que sumariamente, o rumo que uma tal querela aí tem seguido ao longo do tempo.

\section{ESTATUDO JURÍDICO DO ANIMAL EM PORTUGAL}

\section{$2.1 \quad$ NO PLANO JURÍDICO CONSTITUCIONAL}

No que a este domínio diz respeito, podemos afirmar que hodiernamente se tem assistido a um fenómeno de constitucionalização crescente, traduzido na exponencial inscrição da proteção do animal nas Constituições nacionais, como aconteceu na Suíça, Alemanha, Luxemburgo, Brasil e Índia ${ }^{17}$. Em tempos de internormatividade, esta

${ }^{15}$ CABRAL, Filipe, Fundamentação dos direitos dos animais: a existencialidade jurídica, 145; Fernandez Sessarego, Carlos, "Que es ser persona para el Derecho?", in Derecho PUCP, n. ${ }^{\circ} 54,2001$, pp. 18-19; e ainda, Eler, Kalline, "A tutela dos animais pela personalidade: melhor caminho?", in Animais: Bioética e Direito (coord. por Tereza Rodrigues Vieira e Camilo Henrique Silva), Brasil: Portal Jurídico, 2016, p. 41 e ss.

${ }^{16}$ Rejeitamos, porém, a posição adotada, entre nós, por Mafalda Miranda Barbosa que, embora defenda a necessidade de se reconhecerem deveres (indiretos) para com os animais, os vislumbra, de forma questionável, como "meros instrumentos e não como fins em si mesmos", justificando-se a sua utilização pelo ser humano para a satisfação das suas necessidades, sejam elas de ordem física, espiritual ou cultural, com o único limite de que essa atuação não ponha em causa os interesses da humanidade como um todo ou de alguns seres humanos em particular ou, ainda, quando viole os bons costumes. Cf. Barbosa, Mafalda Miranda, "Breve reflexão acerca do problema do estatuto jurídico dos animais", in Boletim da Faculdade de Direito da Universidade de Coimbra, vol. 89, 2013, pp. 250251.

${ }^{17}$ Este processo iniciou-se, em 1992, com a Constituição Suíça - na qual, pela primeira vez, se plasmou a "necessidade de se ter em conta a dignidade da criatura" -, seguida pela Grundgesetz alemã - em cujo art. 20.a se pode ler que "(...) o Estado protege os recursos naturais vitais e os animais, dentro do âmbito da ordem constitucional, através da legislação e de acordo com a lei e o Direito, por meio dos poderes executivo e judicial"- e pela Constituição luxemburguesa - que prevê, no seu art. 11 bis, que "[o Estado] promove a proteção do bem-estar dos animais". Mais recentemente, este movimento também se estendeu à Constituição brasileira, através do seu art. $2255^{\circ}$, o qual dispõe que “(...) incumbe ao poder público (...) proteger a fauna e a flora, sendo vedadas, na forma da lei, as práticas que coloquem em risco a sua função ecológica, provoquem a extinção das espécies ou submetam os animais a crueldade" - embora pareça claro que se prioriza aqui a "função ecológica da fauna", em detrimento da proteção dos animais de maneira individual - e até mesmo à Constituição indiana (v. arts. $48 .^{\circ}, 48 .^{\circ}$ - 
tendência tem-se alargado, igualmente, aos planos internacional e supranacional, deixando-se claro que a proteção do bem-estar dos animais não-humanos é uma preocupação da própria comunidade internacional, o que tem inspirado vários países a tomarem medidas destinadas à sua efetivação ${ }^{18}$.

Embora exista quem considere que este fenómeno é meramente simbólico, somos da opinião de que a proteção, ao nível constitucional, do bem-estar animal é um avanço significativo que pode, inclusivamente, assegurar uma maior eficácia e efetividade da legislação vigente na matéria. Além disso, tal contribui para que o valor do bem-estar animal não vendo limitada a sua tutela ao quadro legal - não ceda automaticamente ante o exercício de alguns direitos e liberdades fundamentais dos seres humanos, como é o caso da liberdade de investigação científica ou da liberdade de fruição cultural.

Entre nós, destaca-se o art. $66^{\circ}$ da Constituição da República Portuguesa (CRP, 1976), que refere que "todos têm o direito a um ambiente de vida humano, sadio e ecologicamente equilibrado e o dever de o defender" (n. ${ }^{\circ} 1$ ). Não se trata aqui de atribuir um qualquer direito ao ambiente propriamente dito - na verdade, estamos ante um "direito

A e 51. -A - este último, impondo um dever de "mostrar compaixão para com as criaturas vivas"). Cf. Le Bot, Olivier, "Grandes évolutions du régime juridique de l'animal en Europe: constitutionnalisation et déréification", in Revue Québécoise de Droit International, vol. 24, 2011, pp. 250-251; e ainda, Pereira, André Dias, “Tiro aos pombos' - a jurisprudência criadora de Direito", in Estudos em Homenagem ao Prof. Doutor António Castanheira Neves - Vol. II (Coord. por Jorge de Figueiredo Dias, J. J. Gomes Canotilho e José de Faria Costa), Coimbra: Coimbra Editora, 2008, p. 544.

18 Veja-se, a título meramente exemplificativo, o disposto na Convenção Internacional para a Regulamentação da Pesca da Baleia, de 2 de dezembro de 1946, na Declaração Universal dos Direitos dos Animais, de 15 de outubro de 1978, e na Convenção das Nações Unidas sobre a Diversidade Biológica, de 5 de junho de 1992. No que respeita ao espólio do Conselho da Europa, destacam-se a Convenção Europeia sobre a Proteção dos Animais em Transporte Internacional, de 13 de dezembro de 1968; a Convenção Europeia para a Proteção dos Animais nos Locais de Criação, de 10 de março de 1976; a Convenção Europeia para a Proteção dos Animais de Abate, de 10 de maio de 1979; a Convenção sobre a Conservação das Espécies Migradoras pertencentes à Fauna Selvagem, de 23 de junho de 1979; a Convenção relativa à Conservação da Vida Selvagem e do Ambiente Natural na Europa, de 19 de setembro de 1979; e a Convenção Europeia para a Proteção dos Animais de Companhia, de 13 de novembro de 1987. Já no âmbito do Direito da União Europeia, a proteção dos animais não-humanos tem sido paulatinamente desenvolvida, desde o silêncio dos tratados constitutivos à consagração expressa da dignidade e do bem-estar dos animais no art. $13 .^{\circ}$ do Tratado sobre o Funcionamento da União Europeia (TFUE). Apesar deste artigo consagrar um compromisso da União Europeia com a proteção do bem-estar animal, ficam salvaguardados os costumes e tradições dos Estados-membros, evitando, deste modo, uma intromissão abusiva na sua autonomia e identidade cultural, o que, no entanto, dificulta a interpretação do preceito e limita a sua relevância normativa. 
circular"19 que assenta na ideia de "proteção de um interesse difuso [dos indivíduos e que] encerra uma justa composição das relações de solidariedade de interesses" ${ }^{20}$. Para além disso, note-se que foi adotada uma visão unitária de ambiente, entendido como o "conjunto de sistemas ecológicos, físicos, químicos e biológicos e de fatores económicos, sociais e culturais" $"$. Para melhor se compreender a extensão deste conceito, parece-nos adequado que olhemos para a nossa Lei de Bases da Política de Ambiente (Lei n. ${ }^{\circ}$ 19/2014, de 14 de abril), mormente o seu art. $10 .^{\circ}$, onde se encontram identificados os componentes ambientais naturais que são objeto da política ambiental nacional: são eles "o ar, a água e o mar, a biodiversidade, o solo e o subsolo, a paisagem". A alínea d) deste preceito menciona também a necessidade de preservação da fauna no conjunto do território nacional. Assim sendo, parece que os animais não-humanos são objeto de proteção constitucional, ainda que apenas na medida em que integram o ambiente ${ }^{22}$. Será de destacar, a nosso ver, que estamos ante um dos casos em que o legislador constituinte impôs expressamente um dever fundamental de proteção - é que a pessoa, enquanto ser relacionável que é, deve ser compreendida como dependente do meio ambiente e, por conseguinte, como titular de uma "obrigação de cuidado para com a Terra"23.

Ainda no nosso texto constitucional, o art. 9.\%) incumbe o Estado de "proteger e valorizar o património cultural do povo português, defender a natureza e o ambiente, preservar os recursos naturais e assegurar o correto ordenamento do território". Vivemos, pois, num Estado de Direito Ambiental, promotor da prossecução de políticas ecologicamente sustentadas e preocupadas com o controlo do risco inerente à sociedade em que hodiernamente nos inserimos ${ }^{24}$. Mais uma vez, se pode concluir que a proteção jurídico-constitucional do animal não-humano se manifesta, entre

\footnotetext{
${ }^{19}$ ANDRADE, José C. Vieira de. Os direitos fundamentais na constituição portuguesa de 1976, 6. ${ }^{\mathrm{a}}$ Edição, Coimbra: Almedina, 2019, p. 61.

${ }^{20}$ CABRAL, Filipe, Fundamentação dos direitos dos animais: a existencialidade jurídica, 199-200.

${ }^{21}$ Gomes Canotilho e Vital Moreira consideram que a CRP adota uma teleologia antropocêntrica, reconhecendo-se o ambiente como valor em si "na medida em que o é para a manutenção da existência e alargamento da felicidade dos seres humanos". Cf. Canotilho, J. J. Gomes / Moreira, Vital, Constituição da República Portuguesa Anotada - Vol. I, 4. . Edição, Coimbra: Coimbra Editora, 2014, p. 845.

${ }^{22}$ LOUREIRO, João, Constituição e Biomedicina - Vol. II, 901.

${ }^{23}$ LOUREIRO, João, Constituição e Biomedicina - Vol. I, Coimbra: Faculdade de Direito da Universidade de Coimbra, 2003, p. 378.

${ }^{24}$ Estamos a referir-nos à Risikogesellschaft de Ulrich Beck. Cf. Beck, Ulrich, La sociedad del riesgo (trad. por Jorge Navarro, Daniel Jiménez e M. Rosa Borrás), Barcelona: Paidós Esenciales, 2019.
} 
nós, de forma reflexa e está direcionada à sua proteção "enquanto espécies e não enquanto espécimes" 25 .

Quem sabe no futuro, em sede de revisão constitucional, não se venha a introduzir um preceito semelhante ao art. 20.a da Constituição alemã - o qual protege os animais como espécimes, nomeadamente contra "danos e sofrimentos evitáveis" -, assim se reconhecendo, ao mais alto nível, a necessidade de se respeitarem os seus interesses (o que, entre nós, já se assume como um verdadeiro imperativo ético ${ }^{26}$ ) e estabelecendo-se as fundações jurídicas necessárias para garantir a sua proteção e efetivação ${ }^{27}$.

\section{$2.2 \quad$ NO PLANO JURÍDICO-CIVIL}

Entre nós, a revisão do estatuto jurídico dos animais no direito civil - que, anteriormente, os qualificava como meras coisas semoventes ou res mobile ${ }^{28}$ - só foi levada a cabo através da Lei n. ${ }^{\circ} 8 / 2017$, de 3 de

\footnotetext{
${ }^{25}$ A proteção das espécies em sentido amplo é vista, sob a ótica do Direito do Ambiente, em razão da função ecológica do animal num determinado ecossistema e as consequências previsíveis da sua retirada desse meio, alterando-se, assim, o equilíbrio ambiental e, consequentemente, a qualidade de vida do Homem. Ou seja, na tutela das espécies, o animal é visto como um autêntico bem ambiental. Cf. Loureiro, João, Constituição e Biomedicina - Vol. I, 378; e ainda, Neves, Helena Telino, "Personalidade jurídica e direitos para que animais?", in Direito (do) Animal (Coord. por Maria Luísa Duarte e Carla Amado Gomes), Coimbra: Almedina, 2016, p. 261.

${ }^{26}$ Exemplo claro desse facto são as chamadas Comissões de Ética Animal. Atualmente, diversos organismos portugueses têm instalações deste tipo, designadamente as faculdades de Medicina, Medicina Veterinária e de Farmácia, instituições dedicadas à investigação e ao desenvolvimento, bem como instituições detentoras de biotérios. Não obstante a diversidade na sua constituição, é clara a existência de um padrão de valores e metas dominante, que passa pela harmonização de práticas na utilização de animais e pela redução efetiva do número de animais utilizados em investigação científica, sua substituição por modelos de procedimento alternativos e pelo devido refinamento das práticas. A sua importância é fundamental, inter alia, em sede de avaliação de projetos e protocolos de investigação, emissão de pareceres para a sua autorização e certificação ou desenvolvimento e implementação de métodos de monitorização da investigação, vigilância e contabilização dos efeitos adversos, irregularidades ou acidentes na investigação. Para maiores desenvolvimentos, v. Ferreira, Ana Elisabete, "Experimentação animal e comissões de ética", in Ética Aplicada-Animais (coord. por Maria do Céu Patrão Neves e Fernando Araújo), Lisboa: Edições 70, 2018, pp. 151-152.

${ }^{27}$ Araújo, Fernando, "The recent development of Portuguese Law in the field of animal rights", in Journal of Animal Law, n. ${ }^{\circ}$ 1, 2005, p. 69.

${ }^{28}$ O Código Civil de 1966 dividia os animais não-humanos em duas categorias: animais selvagens e animais não selvagens. $\mathrm{O}$ art. $202 .^{\circ}$ do CC identificava (e ainda identifica) como "coisa" tudo aquilo que possa ser objeto de relações jurídicas. Assim sendo, e ante o anterior silêncio da nossa lei civil quanto ao estatuto dos animais não-humanos, para a maioria da doutrina, não restavam, pois, dúvidas de que eles estariam incluídos nessa qualificação, tornando-os autênticos objetos de direitos reais. Cf. Barbosa, Mafalda Miranda, "Breve reflexão acerca do problema do estatuto jurídico dos animais", 218. Não obstante, não podemos deixar de observar que, já antes da reforma de 2017, a jurisprudência revelou sinais (ainda que escassos) de recusa da inclusão normativa dos animais entre as coisas - veja-
} 
março (o que, indiscutivelmente, demonstrou um significativo atraso do ordenamento jurídico português, mormente quando comparado com outros, como o austríaco, alemão ou o suíço ${ }^{29}$ ). A partir do momento da sua entrada em vigor, os animais passaram a ser definidos como "seres vivos dotados de sensibilidade" (art. 201. ${ }^{\circ}-\mathrm{B}$ do CC), cuja proteção jurídica se concretiza por via das disposições do Código Civil (CC) e, bem assim, de acordo com o que seja fixado em "legislação especial" (art. 201. ${ }^{\circ}-\mathrm{C}$ do $\mathrm{CC})$.

$\mathrm{Na}$ sequência, procedeu-se em conformidade a algumas alterações relevantes na nossa lei civil, respeitantes à separação entre "coisas" e "animais", à diferente conceção da sua propriedade, a regras que visam proteger o bem-estar do animal em caso de divórcio, bem como a algumas alterações ao Código de Processo Civil (CPC), fixando-se a impenhorabilidade absoluta dos animais de companhia (art. 736.\%) do CPC $)^{30}$. A estas alterações adicionam-se outras tantas no Código Penal $(\mathrm{CP})$, as quais afloraremos mais adiante.

Nos termos do art. 493. ${ }^{\circ}$-A, sob a epígrafe "indemnização em caso de lesão ou morte do animal "31, o responsável pela lesão ou morte de um animal não-humano será obrigado a indemnizar o proprietário deste, ou quem o tenha socorrido, pelas despesas em que tenha incorrido para o respetivo tratamento (n. $\left.{ }^{\circ} 1\right)$. E note-se, esta indemnização é devida, mesmo que o valor das despesas resulte mais elevado do que o valor patrimonial atribuído ao animal (n. ${ }^{\circ}$ 2). Por fim, acrescenta-se que "no caso de lesão de animal de companhia de que tenha provindo a morte, a privação de importante órgão ou membro ou a afetação grave e permanente da sua

se o exemplo do Ac. do Tribunal da Relação do Porto de 21 de novembro de 2016 (Proc. n. ${ }^{\circ}$ 3091/15.6T8GDM.P1).

${ }^{29}$ Para uma análise comparativa, v. Reis, Marisa Quaresma dos, "O papel da ciência na ascensão do Direito Animal e no reconhecimento de direitos aos animais - uma perspetiva comparatista", in Direito (do) Animal (Coord. por Maria Luísa Duarte e Carla Amado Gomes), Coimbra: Almedina, 2016, p. 215 e ss.

${ }^{30}$ PEREIRA, André Dias, FERREIRA, Ana Elisabete, "Novo estatuto jurídico dos animais em Portugal: Direito Civil e experimentação animal”, in Revista Brasileira de Direito Animal, vol. 14, n. ${ }^{\circ}$ 1, 2019, p. 39.

${ }^{31}$ Neste âmbito, e cerca de dois anos antes da reforma, já o Tribunal da Relação do Porto, no Proc. 1813/12.6TBPNF.P1, em 19 de fevereiro de 2015, tinha afirmado que "constitui um dado civilizacional adquirido nas sociedades europeias modernas o respeito pelos direitos dos animais, a aceitação de que os animais são seres vivos carecidos de atenção, cuidados e proteção do homem, e não coisas de que o homem possa dispor a seu bel-prazer, pelo que a relação do homem com os seus animais de companhia possui já hoje um relevo à face da ordem jurídica que não pode ser desprezado justificando que seja atendido como dano não patrimonial suscetível de tutela jurídica o desgosto sofrido com a morte de um animal de companhia". 
capacidade de locomoção, o seu proprietário tem direito, nos termos do n. ${ }^{\circ}$ 1 do artigo $496 .^{\circ}$, a indemnização adequada pelo desgosto ou sofrimento moral em que tenha incorrido, em montante a ser fixado equitativamente pelo tribunal" (n. $\left.{ }^{\circ} 3\right)$.

Se existem autores, como MAFALDA MIRANDA BARBOSA e FILIPE ALBUQUERQUE MATOS, que consideram que estamos ante um preceito que "só se pode compreender por uma intencionalidade funcionalística e ideologicamente marcada" 32 , a verdade é que também não falta quem atente que, desta forma, o legislador decidiu "colocar o interesse de proteção do bem-estar animal à frente da salvaguarda do património do lesante", o que se afigura como uma "solução ajustada à consciência jurídica geral da sociedade hodierna" ${ }^{33}$.

No âmbito do Direito das Coisas, o art. 1302. ${ }^{\circ}$ do CC passou a conter um novo n. ${ }^{\circ}$, de acordo com o qual "podem ainda ser objeto do direito de propriedade os animais, nos termos regulados neste código e em legislação especial". Como consequência, procedeu-se à adaptação de alguns preceitos (art. 1318. $.^{\circ}, 1323 .^{\circ}$ do CC) e ao aditamento do art. $1305 .^{\circ}$ A, que dispõe que os proprietários dos animais devem, no exercício dos seus direitos, assegurar o bem-estar e respeitar as caraterísticas das diferentes espécies, garantindo acesso a água, alimentação e a cuidados médico-veterinários. De forma relevante, deixa-se igualmente claro que "o direito de propriedade de um animal não abrange a possibilidade de, sem motivo legítimo, lhe infligir dor, sofrimento ou quaisquer outros maustratos que resultem em sofrimento injustificado, abandono ou morte". É de louvar que, ao contrário do que ocorreu no âmbito jurídico-penal, a aplicação destes preceitos não tenha sido limitada pelo legislador aos "animais de companhia", estendendo-se igualmente a todos aqueles que, sendo apropriados pelo Homem, não se destinam rigorosamente ao seu entretenimento e acompanhamento.

No plano das relações conjugais, por via da alteração do art. $1733 .^{\circ}$ do CC, os animais de companhia não integram a comunhão geral de bens. Além disso, em caso de divórcio por mútuo consentimento (art. $1775 .^{\circ}$ do CC), impõe-se a existência de acordo sobre o destino dos animais de companhia (que sejam qualificados como "bem comum"). Acrescenta o art. $1793 .^{\circ}$-A do $\mathrm{CC}$ que o destino dos animais de companhia deve ser

\footnotetext{
${ }^{32}$ BARBOSA, Mafalda Miranda, MATOS, Filipe Albuquerque, O novo estatuto jurídico dos animais, 1. ${ }^{a}$ Edição, Coimbra: Gestlegal, 2017, p. 125.

${ }^{33}$ Para maiores desenvolvimentos, v. Pereira, André Dias / Ferreira, Ana Elisabete, "Novo estatuto jurídico dos animais em Portugal: Direito Civil e experimentação animal”, 41-44.
} 
definido tendo por base, inter alia, os interesses de cada um dos cônjuges, dos filhos do casal e do bem-estar do próprio animal.

Referem ANDRÉ DIAS PEREIRA e ANA ELISABETE FERREIRA que esta norma, ao criar obstáculos ao divórcio por acordo entre ambos os cônjuges, poderá estar sujeita a críticas. Afinal de contas, atualmente, o divórcio é possível mesmo na ausência de acordo respeitante à partilha dos bens, mas já não o será caso inexista acordo quanto ao destino a dar ao animal de companhia. Assim, os autores rematam que "o legislador colocou o bem-estar animal à frente do interesse de facilitação de um divórcio sem litígio, o que não será incorreto se pensarmos que o animal carece de um cuidado diário e de decisões imediatas, não podendo adiar-se as decisões relevantes para um momento ulterior" ${ }^{34}$.

Por fim, nos termos do art. 201. ${ }^{\circ}-\mathrm{D}$ do CC, é estabelecido como regime subsidiário aplicável aos animais, as disposições relativas às coisas, desde que não contrárias à sua natureza - o que, nas palavras de CARLOS CASTELO BRANCO, revela uma certa "insuficiência ou imaturidade do novo Estatuto Jurídico dos Animais" 35 .

Antes de prosseguirmos com a nossa análise, cabe, igualmente, uma breve referência a algumas leis nacionais avulsas de relevo em matéria de proteção do bem-estar animal. Desde logo, tal é o caso da já antiga Lei de Proteção dos Animais (LPA) ${ }^{36}$ que, logo no seu art. 1. ${ }^{\circ}$, pontua que "são proibidas todas as violências injustificadas contra animais, considerandose como tais os atos consistentes em, sem necessidade, se infligir a morte, o sofrimento cruel ou prolongado ou lesões graves a um animal"37. Impõese, igualmente, um dever de socorro, na medida do possível, a animais doentes, feridos ou em perigo (n. ${ }^{\circ}$ 2) e proíbem-se um conjunto de atos que possam resultar na degradação ou aniquilação do bem-estar animal (n. ${ }^{\circ} 3$ ). Esta lei é, na perspetiva de parte relevante da doutrina, o principal instrumento jurídico de proteção de animais não-humanos, seja no plano

\footnotetext{
${ }^{34}$ Idem, 40.

${ }^{35}$ BRANCO, Carlos Castelo, "Algumas notas ao Estatuto Jurídico dos Animais", in Revista do Centro de Estudos Judiciários, vol. 1, 2017, p. 91. Também neste sentido, Filipe A. Matos e Mafalda Miranda Barbosa afirmam que "uma tal remissão para o regime das coisas em termos tão genéricos apenas veio revelar que a distinção entre animais e as coisas não se manifesta tão evidente para o próprio legislador". Cf. Mafalda Miranda / Matos, Filipe Albuquerque, O novo estatuto jurídico dos animais, 106.

${ }^{36}$ Estamos a referir-nos à Lei n. ${ }^{\circ} 92 / 95$, de 12 de setembro, com as alterações introduzidas pela Lei n. ${ }^{\circ}$ 19/2002, de 31 de julho, e pela Lei n. ${ }^{\circ}$ 69/2014, de 29 de agosto.

${ }^{37}$ Vide, a este propósito, o Ac. STJ de 19 de outubro de 2004 (Proc. n. ${ }^{\circ}$ 04B3354), relativo à polémica "prática desportiva do tiro com chumbo aos pombos em voo"; e ainda, num sentido mais conforme com o da reforma de 2017, o Ac. TCA-Sul de 2 de dezembro de 2004 (Proc. n. ${ }^{\circ}$ 00375/04).
} 
substantivo, seja no plano adjetivo (v.g., conferindo legitimidade a associações zoófilas para requerer a todas as autoridades e tribunais as medidas preventivas e urgentes necessárias e adequadas para evitar violações em curso ou iminentes sobre animais) ${ }^{38}$. Inquieta, porém, que uma tal proibição de violentar ou maltratar animais não-humanos não passe de uma mera obrigação natural, desprovida de qualquer sanção em caso de violação da mesma ${ }^{39}$. E, infelizmente, com a aprovação da já mencionada Lei n..$^{\circ}$ 69/2014, o legislador, em vez de dotar a LPA de força coercitiva, optou antes por remover do seu texto o anterior art. $9 .^{\circ}$ - que remetia para a lei especial a criação de um regime sancionatório por infração às suas disposições -, eliminando qualquer evidência da sua inexplicável inércia, já que um tal regime, em mais de duas décadas, nunca chegou a ser aprovado. Parece, pois, que a LPA está condenada a seguir como um "mero repositório de mandamentos desprovidos de sanção", não servindo (nem estando em condições de servir!) os fins a que se propõe ${ }^{40} / 41$.

De forma relevante, podemos ainda referir o Decreto-lei $\mathrm{n}^{\circ}$ 276/2001, de 17 de outubro, que estabelece as normas legais tendentes a pôr em aplicação em Portugal a Convenção Europeia de Proteção dos Animais de Companhia e um regime especial para a detenção de animais potencialmente perigosos ${ }^{42}$; o Decreto-lei n. ${ }^{\circ} 59 / 2003$, de 1 de abril, relativo à detenção de animais da fauna selvagem em parques zoológicos; o Decreto-lei n. ${ }^{\circ}$ 112/2013, de 7 de agosto, que regula a utilização de animais para fins científicos; a Lei n. ${ }^{\circ}$ 27/2016, de 23 de agosto, que aprovou medidas para a criação de uma rede de centros de recolha oficial de animais, proibindo o abate de animais errantes abandonados nos canis municipais, devendo esses serviços promover a sua esterilização e reencaminhamento para adoção; ou a recente Lei n. ${ }^{\circ}$ 20/2019, de 22 de fevereiro, que reforça a proteção dos animais utilizados em circos,

\footnotetext{
${ }^{38}$ Branco, Carlos Castelo, "Algumas notas ao Estatuto Jurídico dos Animais", 75.

${ }^{39}$ Gomes, Carla Amado, "Direito dos animais: um ramo emergente?", in ANIMAIS: Deveres e Direitos (coord. por Maria Luísa Duarte e Carla Amado Gomes), Lisboa: ICJP, 2015, p. 63.

${ }^{40}$ Moreira, Alexandra Reis, "Perspetivas quanto à aplicação da nova legislação", in ANIMAIS: Deveres e Direitos (coord. por Maria Luísa Duarte e Carla Amado Gomes), Lisboa: ICJP, 2015, pp. 169-170.

${ }^{41}$ Sempre sublinharemos, não obstante, que uma interpretação teleológica do disposto no $n .^{\circ} 1$ do artigo 483..$^{\circ}$ do CC poderia subsidiar uma solução de efetividade: de acordo com a nossa regra geral da responsabilidade civil, aquele que, com dolo ou mera culpa, violar ilicitamente o direito de outrem ou qualquer disposição legal destinada a proteger interesses alheios fica obrigado a indemnizar o lesado pelos danos resultantes da violação (itálico nosso). Implicará saber se a referência da norma a "interesses alheios" concernirá somente aos titulares autónomos de direitos e deveres, ou também àqueles que a mesma protege - neste caso, os animais - tendo em conta que não se faz qualquer referência a "direitos", mas antes a "interesses" alheios.

${ }^{42}$ Vide, por exemplo, os arts. $6 .^{\circ}$ a $8 .^{\circ}$ deste diploma.
} 
nomeadamente proibindo a utilização de animais selvagens em espetáculos circenses, bem como a sua captura ou treino com esse fim ${ }^{43}$.

Institucionalmente, cabe uma referência à ação da chamada Direção-Geral de Alimentação e Veterinária (DGAV), que tem por missão a definição, execução e avaliação das políticas de segurança alimentar, de proteção animal e de sanidade animal, proteção vegetal e fitossanidade (art. 2.\%1 do Decreto Regulamentar n. 31/2012, de 13 de março); bem como, embora num outro plano, das várias associações e organizações não governamentais que levam a cabo múltiplas ações de promoção e proteção do bem-estar dos animais não-humanos.

\subsection{NO PLANO JURÍDICO-PENAL}

Apesar dos evidentes avanços no domínio juscivilístico, há quem não duvide que é na "órbita do direito penal que se têm verificado os maiores desenvolvimentos legislativos no sentido da proteção dos animais" $" 44$.

Já antes de 2014, a tutela penal concedida ao animal não-humano era levada a cabo de forma indireta e retomava, no essencial, o sistema binário do Código Civil: os animais selvagens protegidos, enquanto "componentes ambientais naturais e essenciais ao equilíbrio do ecossistema, caíam sob o manto protetor dos crimes contra a natureza" (v. arts. $278 .^{\circ}$ e $279 .^{\circ}$ do $\mathrm{CP}$ ); já os animais não selvagens eram tutelados pela via da proteção da propriedade, enquanto "coisas úteis aos seus donos" (v. art. 281. ${ }^{\circ}$ do CP) ${ }^{45} / 46$.

Foi através da Lei no 69/2014, de 29 de agosto, que se levou a cabo uma importante reforma ao Código Penal português, aditando-lhe os

\footnotetext{
${ }^{43}$ Devido à existência de uma norma transitória, só em setembro de 2018 é que se implementou a proibição da occisão de animais em centros de recolha oficiais por motivos de sobrepopulação, sobrelotação, incapacidade económica ou outra que impeça a sua normal detenção (com exceção dos casos relacionados com o estado de saúde ou comportamento do animal). Desta forma, tornou-se inaplicável (e incompreensível) o disposto no art. 5. ${ }^{\circ}$ da LPA.

${ }^{44}$ BRANCO, Carlos Castelo, "Algumas notas ao Estatuto Jurídico dos Animais", 78.

${ }^{45}$ GOMES, Carla Amado, "Desporto e proteção dos animais: por um pacto de não agressão", in $O$ desporto que os tribunais praticam (coord. por José Manuel Meirim), Coimbra: Coimbra Editora, 2014, p. 748.

${ }^{46}$ Tenha-se em consideração, igualmente, as incriminações consagradas na Lei da Caça (Lei n. ${ }^{\circ}$ 173/99, de 21 de setembro) ou no Decreto-Lei n. ${ }^{\circ} 315 / 2009$, de 29 de outubro, que pune criminalmente as lutas entre animais.
} 
arts. 387. $.^{\circ}, 388 .^{\circ}$ e $389 .^{\circ}$, consagradores dos chamados "crimes contra os animais de companhia" 47 (traduzidos num crime de maus tratos e num crime de abandono). Uma das maiores críticas dirigidas a estes preceitos além daquela que advoga a sua inconstitucionalidade por falta de referência constitucional, expressa ou implícita, do bem-jurídico protegido pelos $\operatorname{mesmos}^{48}$ - prende-se com a sua débil e limitada aplicação, sobretudo por se recusar tutela penal, desde logo, aos animais utilizados para fins de exploração agrícola, pecuária ou agroindustrial, bem como aos utilizados para fins de espetáculo comercial ou outros fins legalmente previstos (art. $389 . \%$ do CP). Por outro lado, afigura-se incompreensível que a (in)existência de tutela jurídico-penal seja determinada com base na funcionalidade do animal em causa, i.e. no facto de o mesmo estar ou não destinado ao "entretenimento ou companhia humana"49 (o que, como se sabe, levanta inúmeras dificuldades em termos práticos ${ }^{50}$ ). Como refere ALEXANDRA REIS MOREIRA, "os crimes de maus tratos deviam abranger todos os animais sencientes ou, pelo menos, os animais vertebrados, à semelhança do que dispõe a Lei de Proteção dos Animais alemã”, desde logo, por não ser aceitável que se discriminem os animais agredidos em função da sua utilidade social.

Igualmente questionável é que o nosso legislador tenha limitado a aplicação do art. $387 .^{\circ}$ do $\mathrm{CP}$ aos maus tratos físicos, descurando e esquecendo inúmeras condutas causadoras de sofrimento psicológico, não

\footnotetext{
${ }^{47}$ Houve quem referisse que a consagração deste tipo de crime tinha vindo anunciar, no ordenamento jurídico português, o afirmar da ideia de atribuição de direitos aos animais, já que estas normas penais visavam proteger o interesse do animal à sua integridade física e bem-estar e não apenas os interesses próprios do detentor ou a moral pública. Menezes Cordeiro rejeita esta posição, defendendo que "o facto de se criminalizarem os maus-tratos a animais de companhia desloca a pedra de toque do animal em si, para a especial relação existente entre esta classe concreta de animais e seres humanos", não representando, pois, qualquer prenúncio da ideia de "personificação dos animais não humanos". Subscrevemos, neste ponto, as palavras do autor. Cf. Cordeiro, A. Menezes, "A natureza jurídica dos animais à luz da Lei n. ${ }^{\circ}$ 8/2017, de 3 de março", in Revista de Direito Civil, n. ${ }^{\circ} 2$, 2017, p. 328.

${ }^{48}$ Para maiores desenvolvimentos, v. Sousa, Susana Aires de, "Argos e o Direito Penal (Uma leitura "dos crimes contra os animais de companhia" à luz dos princípios da dignidade e da necessidade)", in Julgar, n. ${ }^{\circ} 32$, 2017, p. 154; e ainda, em geral, Brito, Teresa Quintela de, "Os crimes de maus-tratos e de abandono de animais de companhia: um direito penal simbólico?", in Revista do CEDOUA, n. ${ }^{\circ} 38$, 2016, p. 9 e ss.

${ }^{49}$ FARIAS, Raul, "Dos crimes contra animais de companhia: breves notas", in ANIMAIS: Deveres e Direitos (coord. por Maria Luísa Duarte e Carla Amado Gomes), Lisboa: ICJP, 2015, p. 142.

${ }^{50}$ PEREIRA, Ana Catarina Beirão, "Crimes contra animais de companhia. Enquadramento jurídico, prática e gestão processual", in Crimes contra animais de companhia, Lisboa: Centro de Estudos Judiciários, 2019, pp. 24-26.
} 
raras vezes conducentes a graves patologias e comportamentos anómalos, como a automutilação ${ }^{51}$.

Note-se também que a presente reforma foi acompanhada pela Lei n. ${ }^{\circ} 110 / 2015$, de 26 de agosto, que veio estabelecer o quadro de penas acessórias aplicáveis aos crimes acima mencionados (v. art. 388..$^{\circ} \mathrm{A} \mathrm{CP}$ ).

Segundo cremos, estas alterações tornaram incontroversa a existência de um núcleo duro em torno do bem-estar animal, hoje entendido como um verdadeiro bem-jurídico protegido ${ }^{52}$ (em certos casos, como vimos supra, ao nível constitucional). Além disso, parece finalmente ter desaparecido qualquer "espaço de confusão com a dimensão tradicional, estritamente patrimonial, do crime de dano como único meio de punição de maus tratos dirigidos a animais" ${ }^{53}$. Esta conceção foi precisamente reforçada pela recente Lei n. $^{\circ} 8 / 2017$, nomeadamente tendo em conta as alterações introduzidas em sede dos crimes contra o património (v. alterações aos arts. $203 .^{\circ}$ a $207 .^{\circ}, 209 .^{\circ}$ a $213 .^{\circ}, 227 .^{\circ}$ e $231 .^{\circ}$ a $233 .^{\circ}$ do $\mathrm{CP})^{54}$.

No que respeita ao impacto de tal legislação, segundo dados da Procuradoria-Geral da República (PGR) publicados em janeiro de 2016, durante o ano de 2015, foram registados 1498 inquéritos correspondentes a 1373 investigações pela prática de crimes contra animais de companhia (às quais se juntam mais 22 transitadas de 2014). De um total de 1395 investigações, 772 foram finalizadas ainda em 2015, contando-se apenas com 53 acusações, das quais 32 culminaram com a suspensão provisória do processo; em 10, o Ministério Público decidiu-se pela apresentação de requerimento de aplicação de pena não privativa de liberdade em processo sumaríssimo; e nas restantes 11 foi deduzida acusação para julgamento em processo comum ${ }^{55}$.

Bastante significativa - e, de certo modo, retratando a evolução sociojurídica em matéria de tutela do bem-estar animal e o adensar do

\footnotetext{
${ }^{51}$ MOREIRA, Alexandra Reis, "Perspetivas quanto à aplicação da nova legislação", 159-160 e 163.

${ }^{52}$ FARIAS, Raul, "Dos crimes contra animais de companhia: breves notas", 141.

${ }^{53}$ DELGADO, Pedro Alves, "Desenvolvimento recente da legislação sobre animais em Portugal: uma breve crónica legislativa", in ANIMAIS: Deveres e Direitos (coord. por Maria Luísa Duarte e Carla Amado Gomes), Lisboa: ICJP, 2015, p. 25.

${ }^{54}$ Somam-se ainda alterações levadas a cabo aos arts. $255 .^{\circ}, 355^{\circ}, 356 .^{\circ}$ e $374 .^{\circ}-\mathrm{B}$ a $376 .^{\circ}$ do $\mathrm{CP}$, as quais se limitaram a atualizar a terminologia empregue, passando a referir "coisa ou animal".

${ }^{55}$ Informação disponível em: <http://www.ministeriopublico.pt/destaque/crimes-contra-animais-decompanhia>.
} 
combate a todas as formas de degradação ou violação do mesmo ${ }^{56}$ - foi a condenação, em processo criminal comum decorrido num tribunal da comarca de Setúbal (Proc. n. ${ }^{\circ}$ 90/16.4GFSTB.E1), a 16 meses de pena de prisão efetiva pelo esventramento e consequente morte de uma cadela que se encontrava em trabalho de parto. Em sede de recurso, a referida pena de prisão acabou por ser suspensa pelo Tribunal da Relação de Évora, em Ac. de 19 de junho de 2019 (Proc. 90/16.4GFSTB.E1.E1), por se considerar que a mesma era "excessiva e desadequada". Foi, entretanto, interposto recurso para o Tribunal Constitucional (TC), requerendo-se a fiscalização concreta da constitucionalidade da norma do art. 387..$^{\circ}$ do CP. Espera-se que, quando vier a ser conhecida a decisão dos magistrados do Palácio Ratton, se resolvam definitivamente as dúvidas relativas à conformidade destas normas com o nosso texto constitucional - de preferência, num sentido que dignifique simultaneamente seres humanos e animais, impondo mais humanidade (e responsabilidade!) aos primeiros e protegendo o bem-estar destes últimos.

\section{CONSIDERAÇÕES FINAIS}

Aqui chegados, torna-se evidente que a questão do estatuto jurídico do animal é, ainda hoje, bastante controvertida e desperta reações conflituantes, porventura de impossível conciliação. Parece, porém, inegável que o hodierno pluralismo axiológico acarreta consigo uma crescente e mais intensa consideração dos interesses de animais nãohumanos, procurando-se harmonizar diferentes premissas fomentadoras do progresso económico, científico e cultural e da tutela do bem-estar animal. Como relembra ANDRÉ DIAS PEREIRA, "respeitando os animais promovemos, de forma reforçada, a proteção e dignidade dos seres humanos" $" 57$.

Neste sentido, começámos por dar a conhecer as principais teses em matéria de estatuto (jurídico) dos animais não-humanos. Se as teses que remetem para uma total desconsideração dos interesses dos animais parecem encontrar-se superadas (embora não extintas...), a doutrina divide-

\footnotetext{
56 Neste sentido, vide ainda, por exemplo, o Ac. do TRL de 23 de maio de 2019 (Proc. 346/16.6PESNT.L1-9).

${ }^{57}$ PEREIRA, André Dias, "O bem-estar animal no direito civil e na investigação científica", in Bioética ou Bioéticas na Evolução das Sociedades (coord. por Maria do Céu Patrão Neves), Coimbra: Gráfica de Coimbra, 2005, p. 163.
} 
se na procura do meio mais adequado e eficaz para promover a sua tutela. Por um lado, os defensores da "welfarist approach", focando-se na proteção do bem-estar animal, apelam à criminalização de várias condutas que se traduzam num tratamento cruel dos mesmos. Por outro lado, os defensores da "rights approach" parecem insistir na necessidade de se reconhecerem os animais não-humanos como autênticos titulares de direitos, ignorando, na maioria das vezes, as dificuldades que uma tal "pessoalização" do animal convoca. Por nossa parte, entendemos que, quer do ponto de vista teorético-dogmático, quer prático-jurídico, será sempre mais propício apostar na defesa do reconhecimento de deveres dos seres humanos que têm por objeto os animais e que se destinam à proteção do seu bem-estar, fazendo-se acompanhar de meios jurídicos sancionatórios efetivos para garantir o seu cumprimento.

Em seguida, concluímos não existir, no seio do ordenamento jurídico português, um verdadeiro estatuto jurídico-constitucional do animal não-humano, o qual é protegido pela nossa Constituição apenas como "espécie", mas não como "espécime". Não temos dúvidas, porém, que o bem-estar animal tem adquirido progressivamente o estatuto de bem jurídico relevante, porque exponencialmente intrincado na consciência jurídica comunitária e, nessa medida, merecedor, em crescente intensidade, da mais premente e efetiva proteção jurídica.

Esta tendência foi reforçada, aliás, com as recentes alterações legislativas acarretadas pelo "novo" Estatuto Jurídico dos Animais, agora reconhecidos como "seres vivos dotados de sensibilidade". A discussão em torno da sua oportunidade e conteúdo foi, e continua a ser, intensa no cenário académico e no âmbito jurisprudencial. Aos poucos, o já apelidado "Direito (do) Animal" vai ganhando espessura, havendo mesmo quem the reconheça autonomia científica, fundada na coerência própria de que dispõem um conjunto de normas de proteção animal que apresentam uma fundamentação ontológica e axiológica singular ${ }^{58}$.

Parece, pois, que a ordem jurídica portuguesa tem, sem dúvida, dado importantes passos no sentido de considerar, de forma cada vez mais significativa, os interesses dos animais não-humanos e de promover a tutela do seu bem-estar. Tal não impede, porém, que se afirme que, em muitos aspetos, um tal regime ainda se encontra manchado por inúmeras imperfeições e lacunas. Se é verdade, como escreveu ANTONIO

${ }^{58}$ LEITÃO, Alexandra, "Os espetáculos e outras formas de exibição de animais", in Direito (do) Animal (Coord. por Maria Luísa Duarte e Carla Amado Gomes), Coimbra: Almedina, 2016, pp. 15-16. 
MACHADO, que "caminante no hay camino, se hace camino al andar..." 59 , só esperamos que os ventos da evolução civilizacional nos conduzam a um destino mais risonho e livre de sofrimento e angústia para todos os animais, humanos... e não-humanos!

\section{REFERÊNCIAS BIBLIOGRÁFICAS}

ANDRADE, José C. Vieira de, Os direitos fundamentais na constituição portuguesa de 1976, $6{ }^{\text {a }}$ Edição, Coimbra: Almedina, 2019.

ARAÚJO, Fernando, A hora dos direitos dos animais, Coimbra: Almedina, 2003, p. 334 e ss.

"The recent development of Portuguese Law in the field of animal rights", in Journal of Animal Law, n. ${ }^{\circ}$ 1, 2005, p. 69.

ARISTÓTELES, Política, Lisboa: Vega, 1998, p. 75.

BARBOSA, Mafalda Miranda, "Breve reflexão acerca do problema do estatuto jurídico dos animais", in Boletim da Faculdade de Direito da Universidade de Coimbra, vol. 89, 2013, pp. 250-251.

BARBOSA, Mafalda Miranda / MATOS, Filipe Albuquerque, O novo estatuto jurídico dos animais, 1. ${ }^{a}$ Edição, Coimbra: Gestlegal, 2017, p. 125.

BECK, Ulrich, La sociedad del riesgo (trad. por Jorge Navarro, Daniel Jiménez e M. Rosa Borrás), Barcelona: Paidós Esenciales, 2019.

BRANCO, Carlos Castelo, “Algumas notas ao Estatuto Jurídico dos Animais”, in Revista do Centro de Estudos Judiciários, vol. 1, 2017, p. 91.

CABRAL, Filipe, Fundamentação dos direitos dos animais: a existencialidade jurídica, 71.

CANOTILHO, J. J. Gomes / MOREIRA, Vital, Constituição da República Portuguesa Anotada Vol. I, 4. ${ }^{a}$ Edição, Coimbra: Coimbra Editora, 2014.

CORDEIRO, A. Menezes, “A natureza jurídica dos animais à luz da Lei n. ${ }^{\circ} 8 / 2017$, de 3 de março", in Revista de Direito Civil, n. ${ }^{\circ}$ 2, 2017, p. 328.

DELGADO, Pedro Alves, "Desenvolvimento recente da legislação sobre animais em Portugal: uma breve crónica legislativa", in ANIMAIS: Deveres e Direitos (coord. por Maria Luísa Duarte e Carla Amado Gomes), Lisboa: ICJP, 2015, p. 25.

${ }^{59}$ Excerto retirado da obra "Campos de Castilla: Proverbios y Cantares" (XXIX). 
DUARTE, Maria Luísa, "Direito da união europeia e estatuto jurídico dos animais: uma grande ilusão?”, in Direito (do) Animal (Coord. por Maria Luísa Duarte e Carla Amado Gomes), Coimbra: Almedina, 2016.

FARIAS, Raul, "Dos crimes contra animais de companhia: breves notas", in ANIMAIS: Deveres e Direitos (coord. por Maria Luísa Duarte e Carla Amado Gomes), Lisboa: ICJP, 2015, p. 142.

FERREIRA, Ana Elisabete, "Experimentação animal e comissões de ética", in Ética Aplicada Animais (coord. por Maria do Céu Patrão Neves e Fernando Araújo), Lisboa: Edições 70, 2018, pp. 151-152.

FERNANDES, Miguel Lemos, “Animais experimentais? Só o rato do computador!”, in Direito (do) Animal (Coord. por Maria Luísa Duarte e Carla Amado Gomes), Coimbra: Almedina, 2016, p. 288.

GASSIOT, Olivier, "L'animal, nouvel objet du droit constitutionnel”, in Revue Française de Droit Constitutionnel, n. ${ }^{\circ} 64,2005$, p. 704.

GOMES, Carla Amado, “Direito dos animais: um ramo emergente?”, in ANIMAIS: Deveres e Direitos (coord. por Maria Luísa Duarte e Carla Amado Gomes), Lisboa: ICJP, 2015, p. 63.

LOUREIRO, João, Constituição e Biomedicina - Vol. II, Coimbra: Faculdade de Direito da Universidade de Coimbra, 2003, p. 903.

KAUFMANN, Arthur, Filosofia do Direito, 2. ${ }^{a}$ Edição, Lisboa: Fundação Calouste Gulbenkian, 2007, p. 452.

LE BOT, Olivier, "Grandes évolutions du régime juridique de l'animal en Europe:

constitutionnalisation et déréification", in Revue Québécoise de Droit International, vol. 24, 2011.

LEITÃO, Alexandra, "Os espetáculos e outras formas de exibição de animais", in Direito (do) Animal (Coord. por Maria Luísa Duarte e Carla Amado Gomes), Coimbra: Almedina, 2016, pp. $15-16$.

LOUREIRO, João, Constituição e Biomedicina - Vol. I, Coimbra: Faculdade de Direito da Universidade de Coimbra, 2003. v.I e II.

MOREIRA, Alexandra Reis, "Perspetivas quanto à aplicação da nova legislação", in ANIMAIS: Deveres e Direitos (coord. por Maria Luísa Duarte e Carla Amado Gomes), Lisboa: ICJP, 2015, pp. 169-170.

PEREIRA, Ana Catarina Beirão, "Crimes contra animais de companhia. Enquadramento jurídico, prática e gestão processual", in Crimes contra animais de companhia, Lisboa: Centro de Estudos Judiciários, 2019, pp. 24-26.

PEREIRA, André Dias, "O bem-estar animal no direito civil e na investigação científica", in Bioética ou Bioéticas na Evolução das Sociedades (coord. por Maria do Céu Patrão Neves), Coimbra: Gráfica de Coimbra, 2005, p. 163. 
PEREIRA, André Dias, “'Tiro aos pombos' - a jurisprudência criadora de Direito”, in Estudos em Homenagem ao Prof. Doutor António Castanheira Neves - Vol. II (Coord. por Jorge de Figueiredo Dias, J. J. Gomes Canotilho e José de Faria Costa), Coimbra: Coimbra Editora, 2008 , p. 544.

FERREIRA, Ana Elisabete, "Novo estatuto jurídico dos animais em Portugal: Direito Civil e experimentação animal”, in Revista Brasileira de Direito Animal, vol. 14, n. ${ }^{\circ}$ 1, 2019, p. 39.

REIS, Marisa Quaresma dos, "O papel da ciência na ascensão do Direito Animal e no reconhecimento de direitos aos animais - uma perspetiva comparatista", in Direito (do) Animal (Coord. por Maria Luísa Duarte e Carla Amado Gomes), Coimbra: Almedina, 2016, p. 215 e ss. 